\title{
Reference values for lung function tests. III. Carbon monoxide diffusing capacity (transfer factor)
}
J.A. Neder ${ }^{1}$,
S. Andreoni2,
C. Peres ${ }^{2}$ and
L.E. Nery ${ }^{3}$

\author{
1Department of Physiology, St. George's Hospital Medical School, \\ University of London, London, UK \\ ${ }^{2}$ Departamento de Medicina Preventiva e Social, and \\ ${ }^{3}$ Disciplina de Pneumologia, D epartamento de Medicina, \\ Escola Paulista de Medicina, Universidade Federal de São Paulo, \\ São Paulo SP, Brasil
}

\section{Correspondence \\ L.E. Nery \\ Disciplina de Pneumologia EPM, UNIFESP \\ Rua Botucatu, 740, 30 andar \\ 04023-062 São Paulo, SP \\ Brasil \\ Fax: +55-11-570-2127 \\ E-mail: lenery@ pneumo.epm.br}

Research partially supported by CNPq and FAPESP. J.A. Neder was the recipient of a post-doctoral fellowship from FAPESP (No. 95/9843-0).

Received April 30, 1998 Accepted January 13, 1999

\section{Abstract}

Carbon monoxide diffusing capacity $\left(\mathrm{DL}_{\mathrm{CO}}\right)$ or transfer factor $\left(\mathrm{TL}_{\mathrm{CO}}\right)$ is a particularly useful test of the appropriateness of gas exchange across the lung alveolocapillary membrane. With the purpose of establishing predictive equations for $\mathrm{DL}_{\mathrm{CO}}$ using a non-smoking sample of the adult Brazilian population, we prospectively evaluated 100 subjects ( 50 males and 50 females aged 20 to 80 years), randomly selected from more than 8,000 individuals. Gender-specific linear prediction equations were developed by multiple regression analysis with single breath (SB) absolute and volume-corrected (VA) $\mathrm{DL}_{\mathrm{CO}}$ values as dependent variables. In the prediction equations, age (years) and height $(\mathrm{cm})$ had opposite effects on $\mathrm{DL}_{\mathrm{CO}} \mathrm{SB}\left(\mathrm{ml} \mathrm{min}^{-1} \mathrm{mmHg}^{-1}\right)$, independent of gender $(-0.13$ (age) +0.32 (height) -13.07 in males and -0.075 (age) +0.18 (height) +0.20 in females). On the other hand, height had a positive effect on $\mathrm{DL}_{\mathrm{CO}} \mathrm{SB}$ but a negative one on $\mathrm{DL}_{\mathrm{CO}} \mathrm{SB} /$ $\mathrm{VA}_{\mathrm{A}}(\mathrm{P}<0.01)$. We found that the predictive values from the most cited studies using predominantly Caucasian samples were significantly different from the actually measured values $(\mathrm{P}<0.05)$. Furthermore, oxygen uptake at maximal exercise $\left(\dot{\mathrm{V}}_{2} \mathrm{max}\right)$ correlated highly to $\mathrm{DL}_{\mathrm{CO}} \mathrm{SB}(\mathrm{R}=0.71, \mathrm{P}<0.001)$; this variable, however, did not maintain an independent role to explain the $\dot{\mathrm{V}} \mathrm{O}_{2}$ max variability in the multiple regression analysis $(\mathrm{P}>0.05)$. Our results therefore provide an original frame of reference for either $\mathrm{DL}_{\mathrm{CO}} \mathrm{SB}$ or $\mathrm{DL}_{\mathrm{CO}} \mathrm{SB} / \mathrm{VA}$ in Brazilian males and females aged 20 to 80 years, obtained from the standardized single-breath technique.

\section{Introduction}

Carbon monoxide (CO) diffusing capacity $\left(\mathrm{DL}_{\mathrm{CO}}\right)$ measures the transfer of a diffusion-limited gas (CO) across the lung alveolocapillary membrane. $\mathrm{CO}$ combines with hemoglobin $(\mathrm{Hb})$ about 210 times more readily than does oxygen and in the presence
Key words

- Lung diffusing capacity

- Pulmonary function tests

- Maximal oxygen

consumption of normal amounts of $\mathrm{Hb}$ and normal ventilatory function, the primary limiting factor to $\mathrm{CO}$ diffusion is the status of the membrane $(1,2)$. Traditionally, resistances to the diffusion of $\mathrm{CO}\left(\right.$ or $\left.\mathrm{O}_{2}\right)$ are listed in series as follows: $1 / \mathrm{DL}=1 / \mathrm{Dt}+1 / \mathrm{Dp}+1 / \theta \mathrm{Vc}$, where DL is the diffusing capacity of the whole lung, $\mathrm{Dt}$ is the pulmonary tissue component, 
Dp is the plasma component, $\theta$ is the rate at which $1 \mathrm{ml}$ of blood takes up the gas and $\mathrm{V}_{\mathrm{C}}$ is the capillary blood volume in $\mathrm{ml}(1)$. Therefore, lung diffusing capacity may be changed by "membrane" factors such as surface area, thickness of the gas pathway and the membrane composition or by $\theta \mathrm{VC}$ factors (i.e., changes in the operative capillary volume, $\mathrm{Hb}$ concentration, $\mathrm{PO}_{2}, \mathrm{pH}, \mathrm{PCO}_{2}$, temperature and backpressure for $\mathrm{CO})(1) . \mathrm{DL}_{\mathrm{CO}}$ is reduced in several conditions such as interstitial, obstructive and vascular disorders of the lungs. Additionally, there is a definite role for the $\mathrm{DL}_{\mathrm{CO}}$ measurement in predicting arterial desaturation during exercise and in the evaluation of impairment/disability. Conversely, there are some conditions in which an abnormally increased $\mathrm{DL}_{\mathrm{CO}}$ can be seen, e.g., polycythemia, pulmonary hemorrhage, increase in pulmonary blood flow (left-to-right shunt) and possibly bronchial asthma (1-4).

The rather complex anatomical and physiological aspects which underlie $\mathrm{DL}_{\mathrm{CO}}$ explain i) its wide clinical and research applications and ii) the need to use either a carefully standardized technique or representative reference values. As for most biological measurements, normative values for $\mathrm{DL}_{\mathrm{CO}}$ should ideally be obtained from a randomly selected, geographically related population in order to improve accuracy and reduce variability (5). To the best of our knowledge, however, there is no published source of reference values for $\mathrm{DL}_{\mathrm{CO}}$ which have been obtained from a randomly selected sample of the general population in Brazil. This study is the third communication in a sequence of descriptions of reference values for lung function tests (other than spirometry) obtained in a randomized sample of urban, adult Brazilians $(6,7)$. This report, therefore, is primarily concerned with the description of an original set of gender-specific predictive equations for carbon monoxide diffusion capacity of the lungs $\left(\mathrm{DL}_{\mathrm{CO}}\right)$ using the single-breath (SB) standardized technique $(3,4,8-10)$.

\section{Material and Methods}

\section{Study design and subjects}

The exclusion criteria and the ethnic, demographic, anthropometric, spirometric and regular physical activity profile of the population evaluated was previously described in detail (6).

\section{Protocol}

The subjects were submitted to the protocol following this sequence: a) complete clinical, hematological and cardiorespiratory evaluation at rest; b) evaluation of the regular physical activity pattern by a questionnaire (5); c) determination of maximal inspiratory and expiratory pressures and maximal voluntary ventilation; d) spirometry and static lung volume measurements; e) determination of the lung diffusion capacity for carbon monoxide, and f) cardiopulmonary exercise tests on a cycle ergometer (a squarewave protocol at $25 \mathrm{~W}$ for subject familiarization and, after $1 \mathrm{~h}$, a maximal ramp-incremental exercise test). On a separate day, g) total and regional body composition was evaluated by dual energy X-ray absorptiometry (DEXA) and h) knee strength measured by isokinetic dynamometry. A detailed description of the techniques cited in items $\mathrm{a}, \mathrm{b}, \mathrm{c}, \mathrm{d}, \mathrm{f}, \mathrm{g}$ and $\mathrm{h}$ was given in studies I and II in this series $(6,7)$.

Before the tests, the procedures, including the known risks, were described in detail and written informed consent (as approved by the Institutional Medical Ethics Committee) was obtained from all subjects. The subjects did not receive remuneration.

\section{Carbon monoxide diffusing capacity}

$\mathrm{DL}_{\mathrm{CO}}$ was measured by the modified Krogh technique (single-breath) using a computer-based automated system (PF-DX, Medical Graphics Corp., St. Paul, MN, USA) 
(3). The procedure was previously explained and demonstrated by a designated technician. The subjects wore noseclips and were in the seated position. All tests were performed in the same laboratory at a barometric pressure of 685-699 $\mathrm{mmHg}$, temperature between $22-28^{\circ} \mathrm{C}$ and $680 \mathrm{~m}$ above sea level (São Paulo, Southeast Brazil).

In this test, the subject, after exhaling to residual volume (RV), inspires a vital capacity (VC) breath of a gas mixture from the system $\left(0.3 \% \mathrm{CO}, 10 \% \mathrm{He}, 21 \% \mathrm{O}_{2}, \mathrm{~N}_{2}\right.$ balance) to total lung capacity (TLC), then holding the breath for $10 \mathrm{~s}$. At the end of the breath-hold, the subject exhales a fixed washout volume $(750 \mathrm{ml})$ and a sample of alveolar gas $(500 \mathrm{ml})$ is taken for analysis with a multiple-gas chromatographic analyzer (2$4,8-12)$. Considering that the $\mathrm{DL}_{\mathrm{CO}}$ is the rate of uptake of $\mathrm{CO}$ in $\mathrm{ml}$ of gas standard temperature and pressure, dry (STPD) per minute and per $\mathrm{mmHg}$ driving pressure of $\mathrm{CO}$, then:

$$
\mathrm{DL}_{\mathrm{CO}}=\mathrm{VCO} / \mathrm{PACO}-\mathrm{PcCO}
$$

where $\mathrm{VCO}$ is the uptake of $\mathrm{CO}$ in $\mathrm{ml}, \mathrm{PACO}$ is the average alveolar pressure of $\mathrm{CO}$, and $\mathrm{PcCO}$ is the mean capillary pressure for $\mathrm{CO}$ (i.e., flow/pressure difference or conductance). Assuming that the change in $\mathrm{PcCO}$ is inconsequential due to the strong affinity of $\mathrm{CO}$ for $\mathrm{Hb}$, and the carboxyhemoglobin $(\mathrm{COHb})$ level is very low, the denominator can be reduced to PACO. The concentration of $\mathrm{CO}$ in the alveolar gas at the beginning of the breath-hold $\left(\mathrm{FACO}_{0}\right)$ is computed as:

$$
\mathrm{FACO}=\mathrm{FICO} \times \mathrm{FAHe} / \mathrm{FIHe}
$$

where $\mathrm{FICO}$ is the inhaled fraction of $\mathrm{CO}$ (0.003), FAHe is the fraction of $\mathrm{He}$ in the end-tidal sample (alveolar) and FIHe is the fraction of $\mathrm{He}$ in inspired gas (0.10). The $\mathrm{DL}_{\mathrm{CO}} \mathrm{SB}$ can then be calculated as:

$$
\begin{gathered}
\mathrm{DL}_{\mathrm{CO}} \mathrm{SB}=\mathrm{VA} \times 60 /(\mathrm{Pb}-47) \times \mathrm{T} \times \\
\left(\mathrm{Ln} \mathrm{FACO} \mathrm{FACO}_{\mathrm{T}}\right)
\end{gathered}
$$

where $\mathrm{VA}$ is the alveolar volume calculated from the single-breath dilution of $\mathrm{He}(\mathrm{VI} /$
(FAHe/FIHe)) x STPD correction factor, 60 is the correction from seconds to minutes, $\mathrm{Pb}$ is the barometric pressure, 47 is the water vapor pressure at $37^{\circ} \mathrm{C}$, $\mathrm{T}$ is the breath-hold interval, $\mathrm{Ln}$ is the natural logarithm and $\mathrm{FACO}_{\mathrm{T}}$ is the fraction of $\mathrm{CO}$ at the end of diffusion (2).

The following additional technical aspects were standardized $(3,4,9)$ : inspired volume was always higher than $90 \%$ of $\mathrm{VC}$ and this was attained in less than $2.5 \mathrm{~s}$; the timing method used was that of Ogilvie et al. (13) (from the beginning of inspiration to the beginning of alveolar sample) and both Mueller and Valsalva maneuvers were avoided by instructing the subjects to perform a relaxed breath-holding maneuver. At least two tests were performed, with the results being within $10 \%$ or $3 \mathrm{ml} \mathrm{CO} \mathrm{m^{-1 }}$ $\mathrm{mmHg}^{-1}$ (STPD) whichever was greater. The results were reported in $\mathrm{ml}$ of $\mathrm{CO}$ per $\mathrm{mmHg}$ of driving pressure at $0^{\circ} \mathrm{C}, 760 \mathrm{mmHg}$, dry (i.e., STPD) either in absolute or VA corrected values.

\section{Data analysis}

All data obtained were entered into a personal computer for statistical analysis using the Statistical Package for the Social Sciences $^{\mathrm{TM}}$ - SPSS (14). The statistical approach used for data analysis (15) was described in details by Neder et al. (6).

\section{Results}

Means \pm SD values of the variables are presented in Table 1: although males presented higher absolute values than females, volume-corrected values were not significantly different between sexes $(\mathrm{P}>0.05)$. As anticipated, TLC and height showed the strongest correlation with $\mathrm{DL}_{\mathrm{CO}} \mathrm{SB}(\mathrm{R}=0.70$ and 0.68 , respectively) but weight correlated less $(\mathrm{R}=0.37)$. Age presented a moderate negative relationship with the diffusing capacity $(\mathrm{R}=-0.36)$ (Figure 1, Table 2). When these 
Table 1 - Absolute and alveolar volume-corrected (VA) values of single-breath carbon monoxide diffusing capacity $\left(\mathrm{DL}_{\mathrm{CO}} \mathrm{SB}\right)$ in males and females by age group.

Data are reported as means $\pm S D$. +Significant effect between age groups within sex $(P<0.05) ; 20-29$ and 3039 age groups vs $40-49$ to $70-80$ groups. ${ }^{*}$ Significant effect between sex groups $(P<0.05)$; males vs females by age group.

\begin{tabular}{lccccc}
\hline \multirow{2}{*}{$\begin{array}{l}\text { Age } \\
\text { years })\end{array}$} & \multicolumn{2}{c}{ Males $(\mathrm{N}=50)$} & & \multicolumn{2}{c}{ Females $(\mathrm{N}=50)$} \\
\cline { 2 - 3 } \cline { 5 - 6 } & $\begin{array}{c}\text { DLcoSB } \\
\left(\mathrm{ml} \mathrm{min}^{-1} \mathrm{mmHg}^{-1}\right)\end{array}$ & $\begin{array}{c}\text { DLcoSBNA } \\
\left(\mathrm{ml} \mathrm{min}^{-1} \mathrm{mmHg}^{-1} \mathrm{l}^{-1}\right)\end{array}$ & & $\begin{array}{c}\text { DLcoSB } \\
\left(\mathrm{ml} \mathrm{min}^{-1} \mathrm{mmHg}^{-1}\right)\end{array}$ & $\begin{array}{c}\text { DLcoSBNA } \\
\left(\mathrm{ml} \mathrm{min}^{-1} \mathrm{mmHg}^{-1} \mathrm{l}^{-1}\right)\end{array}$ \\
\hline $20-29$ & $39.9 \pm 5.7^{+*}$ & $5.87 \pm 0.68^{+}$ & & $27.7 \pm 1.9^{+}$ & $5.83 \pm 0.63^{+}$ \\
$30-39$ & $37.3 \pm 6.0^{+*}$ & $5.47 \pm 0.67^{+}$ & & $27.1 \pm 2.6^{+}$ & $5.52 \pm 0.72^{+}$ \\
$40-49$ & $29.6 \pm 5.3^{*}$ & $4.91 \pm 0.85$ & & $23.9 \pm 2.3$ & $5.20 \pm 1.07$ \\
$50-59$ & $30.7 \pm 4.0^{*}$ & $5.14 \pm 1.20$ & & $23.4 \pm 2.1$ & $4.99 \pm 0.70$ \\
$60-69$ & $28.0 \pm 6.2^{*}$ & $5.11 \pm 0.56$ & & $23.5 \pm 3.7$ & $5.12 \pm 0.64$ \\
$70-80$ & $29.3 \pm 4.8^{*}$ & $4.62 \pm 1.09$ & & $21.1 \pm 1.5$ & $5.1 \pm 0.70$
\end{tabular}

variables were more properly considered in a multiple regression analysis, only height and age remained with an independent predictive power in both sexes (Table 3). Similar findings were also found in regard to $\mathrm{DL}_{\mathrm{CO}} \mathrm{SB} / \mathrm{VA}$ prediction. However, we found a rather negative effect of height on the prediction of this variable, independent of gender (Table 3). After application of the predicted residual sum of squares (PRESS) method in the regression equations, we found only a mild effect in the $\mathrm{R}$ and standard error of the estimate (SEE) original values (RPRESS ranging from 0.012-0.045 units below original $R$ and SEEPRESS values being 5-9\% higher than the original SEE values). This suggests that these equations might be used on other similar samples without a significant loss in accuracy (16).

We also evaluated the predictive accuracy of some of the most cited studies for $\mathrm{DL}_{\mathrm{CO}}$ prediction which used predominantly Caucasian subjects $(3,17,18)$. Interestingly, we found that the performance of the equations was strongly influenced by the magnitude of the observed value: there was an overestimation of the lower values and an underestimation of the higher ones $(\mathrm{P}<0.05)$. These findings were more clearly evident in the male group (Figure 2). Similar results were obtained regarding the alveolar volume-corrected values (Figure 3).

Finally, we investigated the relationship between maximum aerobic power $\left(\dot{\mathrm{V}}_{2} \max \right)$ and $\mathrm{DL}_{\mathrm{CO}} \mathrm{SB}$ (Figure 4), Although these variables were highly correlated in a bivariate analysis $(\mathrm{R}=0.70), \mathrm{DL}_{\mathrm{CO}} \mathrm{SB}$ did not maintain an independent predictive role for $\mathrm{V}_{2}$ max in a multiple regression model which considered gender, age, height and weight (data not shown).

\section{Discussion}

This study is the third paper in a sequence of reports of reference values for lung function tests (other than spirometry) which were derived from a randomly selected sample of sedentary, healthy adult Brazilians $(6,7)$. We confirmed previous studies reporting that age and height are independent predictors of both absolute and volume-corrected values of carbon monoxide diffusion capacity ( $\mathrm{DL}_{\mathrm{CO}} \mathrm{SB}$ and $\mathrm{DL}_{\mathrm{CO}} \mathrm{SB} / \mathrm{VA}$, respectively). The equations generated in this study, however, were at significant variance with some of the most cited previous studies which used predominantly Caucasian samples $(3,17,18)$. In- 
terestingly, there was no systematic overestimation of the observed values despite reports of lower values in populations other than Caucasians $(3,4,19)$. These results are consistent with the statistical notion that reference values for some biological measurements should be obtained ideally from a randomly selected sample with a general profile similar to that of the population to which these values will be applied (5).

The negative correlation of age with $\mathrm{DL}_{\mathrm{CO}} \mathrm{SB}$ could be anticipated since aging is related to a decline in the total area of the alveolocapillary membrane and the capillary operating volume and to an increase in both ventilation-perfusion $(\dot{\mathrm{V}} / \mathrm{Q})$ mismatch and in the closing capacity of the small airways (i.e., closing volume plus residual volume) $(1,2,20)$. Additionally, older subjects may show a small, but significant, reduction in TLC (1). On the other hand, height is closely related to lung volumes and therefore positively associated with $\mathrm{DL}_{\mathrm{CO}}$. The negative effect of height in the $\mathrm{DL}_{\mathrm{CO}} \mathrm{SB} / \mathrm{VA}$ ratio, however, is probably linked to a non-linear relationship between VA and height in the taller subjects, i.e., there is a higher increase in the denominator of this ratio with increasing height (21). Although weight was also positively associated with $\mathrm{DL}_{\mathrm{CO}} \mathrm{SB}$ (Table 1), this variable did not continue to be an independent predictor when considered in addition to age and height (Table 3). On the other hand, Ray et al. (22), in a study of morbidity among obese subjects, found that $\mathrm{DL}_{\mathrm{CO}} \mathrm{SB}$ decreases when the weight-to-height ratio is greater than 1.0; because of our exclusion criteria, however, these subjects were not evaluated in the present study.

The wide variability in the values for $\mathrm{DL}_{\mathrm{CO}} \mathrm{SB}$ predicted from different equations and within the same set of equations (our $\mathrm{R}^{2}$ values varied from 0.22 to 0.36 , for example - Table 3) seems of such magnitude that errors in gas measurements, poor standardization and different computational algorithms could be involved. In this study, we chose to
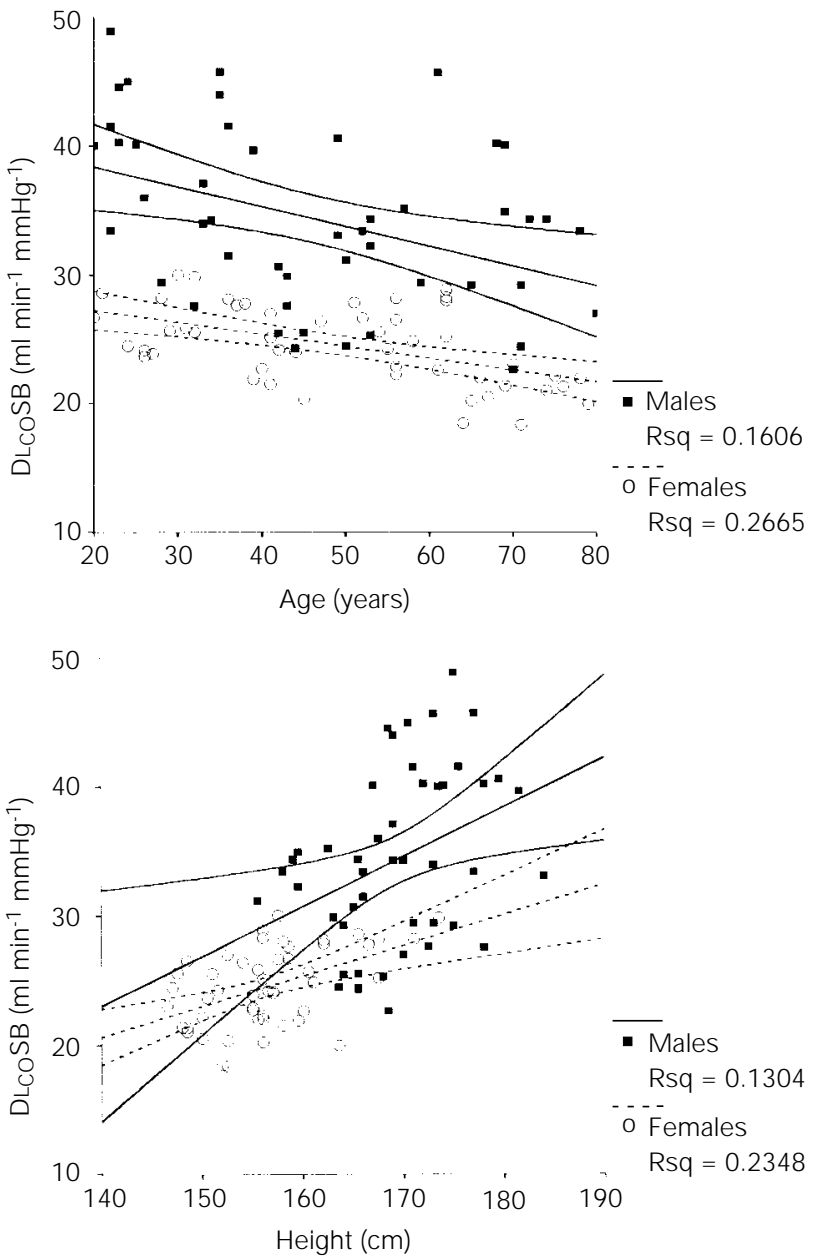

Figure 1 - Carbon monoxide diffusing capacity $\left(\mathrm{DLCOSB}_{\mathrm{C}}\right)$ as a function of age (upper panel) and height (lower panel) in 100 healthy sedentary subjects. Regression lines are presented with the corresponding 95\% confidence limits $(\mathrm{CL})$

Males: $y=-0.15$ (age) +41.4 (CL for $x=12.3$ ) or 0.38 (height) $-30.9(C L=$ 12.4), $\mathrm{P}<0.05$

Females: $\mathrm{y}=-0.09$ (age) +29.1 (CL for $\mathrm{x}=4.8$ ) or 0.23 (height) $-12.4(\mathrm{CL}=$ 5.2), $\mathrm{P}<0.01$

Rsq is the coefficient of determination.

Table 2 - Correlation matrix.

$\mathrm{V}_{2}$ max: Maximum oxygen uptake; TLC: total lung capacity; DLCo: single-breath carbon monoxide diffusing capacity. ${ }^{*} \mathrm{P}<0.05$. ${ }^{* *} \mathrm{P}<0.01$.

\begin{tabular}{lllllll}
\hline & Age & Height & Weight & $\dot{\mathrm{VO}}_{2}$ max & TLC & DLCOSB \\
\hline Age & 1.00 & & & & & \\
Height & $-0.22^{*}$ & 1.00 & & & & \\
Weight & -0.01 & $0.54^{* *}$ & 1.00 & & & \\
VO $_{2}$ max & $-0.61^{* *}$ & $0.67^{* *}$ & $0.50^{* *}$ & 1.00 & & \\
TLC & $-0.24^{*}$ & $0.85^{* *}$ & $0.49^{*}$ & $0.67^{* *}$ & 1.00 & \\
DLCOSB & $-0.36^{* *}$ & $0.68^{* *}$ & $0.37^{* *}$ & $0.71^{* *}$ & $0.70^{* *}$ & 1.00
\end{tabular}


Figure 2 - Single-breath carbon monoxide diffusing capacity (DLCoSB) observed and predicted values by previous equations $(3,17,18)$ as a function of the actually measured values in males and females aged 20 to 80 years. Dashed lines delimit the difference between observed and predicted values which could be accounted for by the inherent error in measurements.
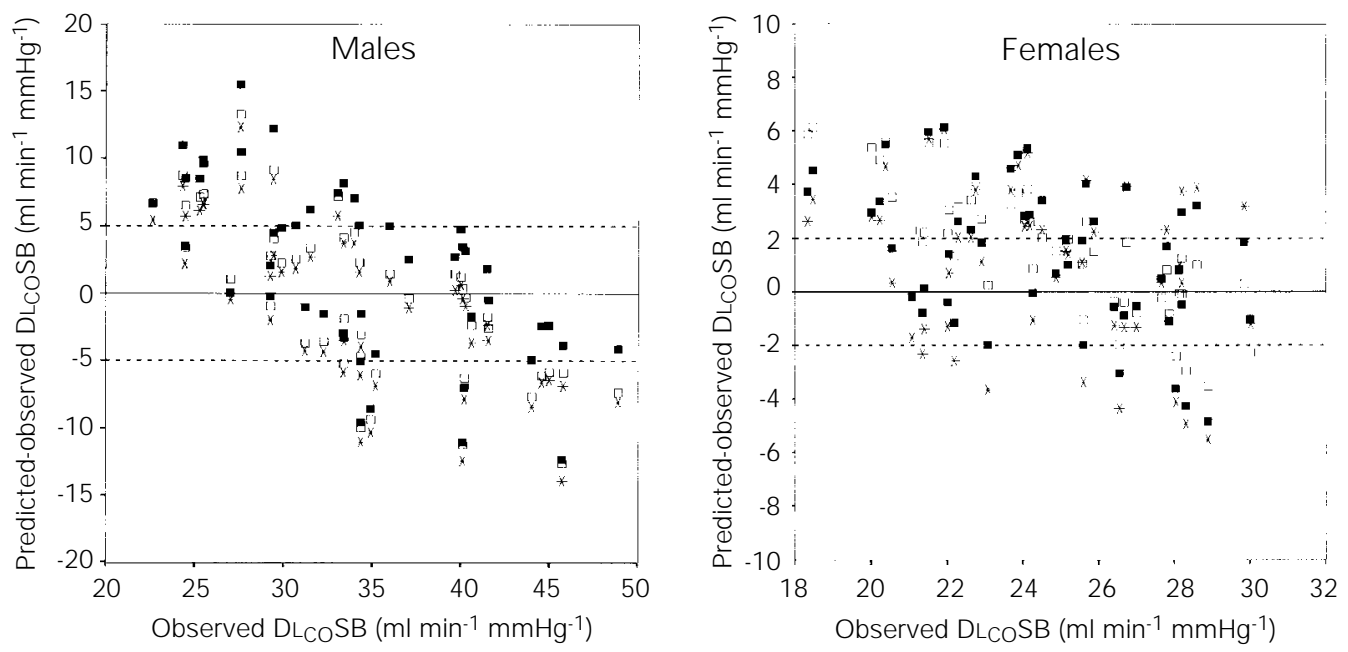

$\square$ Paoletti et al. (17) $\quad$ Knudson et al. (18) * Crapo and Gardner (3)

Table 3 - Linear prediction equations for absolute and alveolar volume-corrected (VA) values of single-breath carbon monoxide diffusing capacity (DLCoSB) in males and females aged 20 to 80 years.

Values in the columns represent coefficient estimates followed by the respective standard error of estimate. $\mathrm{R}^{2}=$ Coefficient of determination; RSE = residual standard error.

\begin{tabular}{lcccccc}
\hline Variable & Sex & Age (years) & Height $(\mathrm{cm})$ & Constant & $\mathrm{R}^{2}$ & RSE \\
\hline $\begin{array}{l}\text { DLCOSB } \\
\left(\mathrm{ml} \mathrm{min}^{-1} \mathrm{mmHg}^{-1}\right)\end{array}$ & Male & $-0.13 \pm 0.05$ & $0.32 \pm 0.14$ & $-13.07 \pm 24.67$ & 0.245 & 6.01 \\
& Female & $-0.075 \pm 0.02$ & $0.18 \pm 0.05$ & $0.20 \pm 9.41$ & 0.365 & 2.42 \\
$\begin{array}{l}\text { DLCOSBNA } \\
\left(\mathrm{ml} / \mathrm{min}^{-1} / \mathrm{mmHg}^{-1} \mathrm{I}^{-1}\right)\end{array}$ & Male & $-0.031 \pm 0.007$ & $-0.053 \pm 0.019$ & $15.55 \pm 3.29$ & 0.337 & 0.83 \\
& Female & $-0.014 \pm 0.004$ & $-0.023 \pm 0.013$ & $9.55 \pm 2.68$ & 0.220 & 0.74
\end{tabular}

use the well-standardized single-breath technique considering its availability, simplicity and lower influence from the $\dot{\mathrm{V}} / \dot{\mathrm{Q}}$ mismatch than other techniques $(1,2)$. The more significant disadvantages are related to the need for a breath-holding maneuver, the variability in maximal attained lung volume, and its restricted application during moderate to severe dynamic exercise $(1,2)$. Most of these problems, however, may be overcome by using a carefully standardized technique (see Methods). The other confounding factors in the $\mathrm{DL}_{\mathrm{CO}}$ analysis, such as low $\mathrm{PAO}_{2}$ and high $\mathrm{COHb}$, were avoided by controlling the $\mathrm{PIO}_{2}$ in the test gas and using non-smokers. Additionally, resting condition, body posi- tion and the time period were standardized. Finally, the study of only non-anemic subjects (mean $\pm \mathrm{SD}$ values and range of $\mathrm{Hb}$ in $\mathrm{mg} \%$ were: $15.6 \pm 1.6,13-20.6$ in males and $13.4 \pm 1.3,12.1-18.6$ in females) allowed the $\mathrm{Hb}$ correction factor to be dispensed with. In anemic patients, however, test results should be expressed in both absolute and Hb-corrected values (8).

A particularly noticeable result was the non-parallel error of the North American and European equations in predicting $\mathrm{DL}_{\mathrm{CO}} \mathrm{SB}$ and $\mathrm{DL}_{\mathrm{CO}} \mathrm{SB} / \mathrm{VA}$ in both males and females, i.e., there was significant overestimation at low values and underestimation at high values (Figures 2 and 3). Although the 

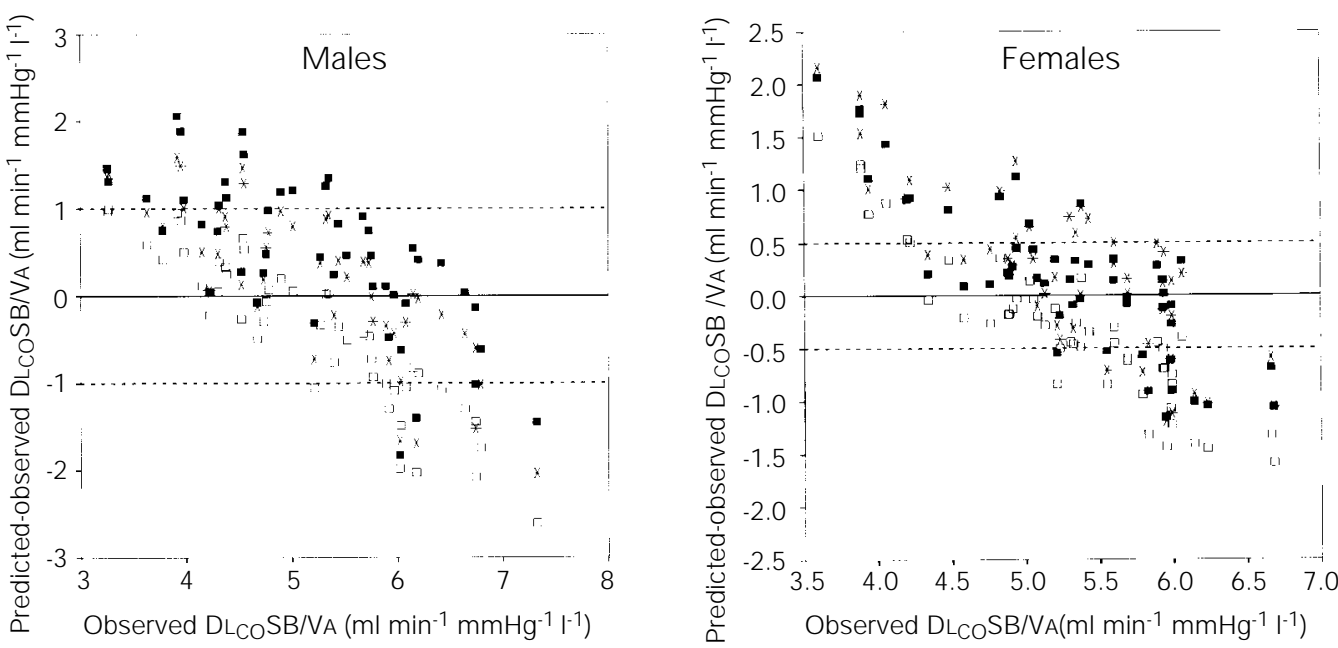

Figure 3 - Volume-corrected (VA) single-breath carbon monoxide diffusing capacity (DLCoSB/NA) observed and predicted values by previous equations $(3,17,18)$ as a function of the actually measured values in males and females aged 20 to 80 years. Dashed lines delimit the difference between observed and predicted values which could be accounted for by the inherent error in measurements.

underlying mechanisms are still speculative, it is noteworthy that we found identical results regarding the static LV prediction (6). Apart from potential small but additive differences in any of the several anatomical and physiological determinants of the lung diffusion capacity (1-4), a statistical explanation could also be hypothesized: it is well known that a weaker prediction power is expected at the extremes of the regression, notably when the original sample is very different from the sample studied (15). Therefore, an overestimation at low values would be predictable if one considers that few subjects with anthropometric characteristics similar to those of our older and shorter subjects were evaluated in the previous Caucasian-based studies. On the other hand, it is tempting to suggest that, possibly due to secular trends (5), younger and taller Brazilians would present higher values than expected for their older (and shorter) counterparts. Although a non-linear adjustment did not produce a better fit for our cross-sectional data (Figure 1), this hypothesis warrants further consideration using appropriate longitudinal evaluations.

Another interesting finding was the strong correlation between $\dot{\mathrm{VO}}_{2} \max$ and $\mathrm{DL}_{\mathrm{CO}} \mathrm{SB}$.

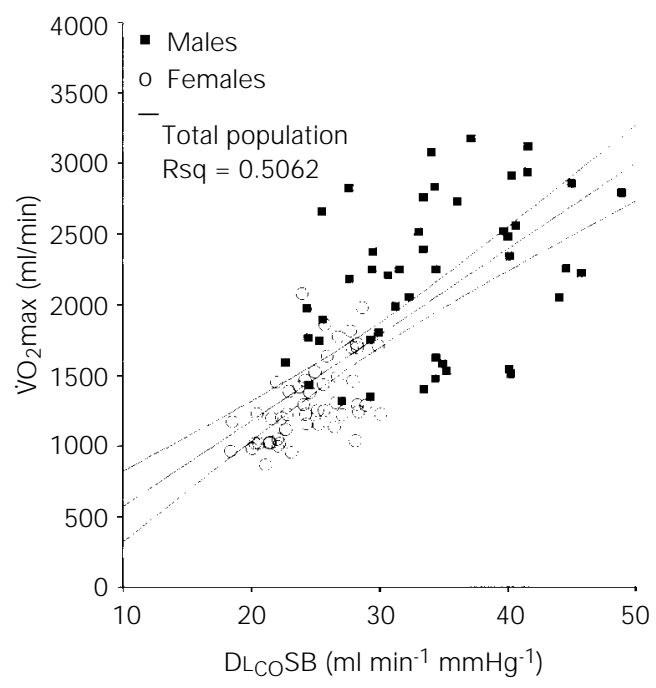

A true limitation of $\dot{\mathrm{V}}_{2}$ max by pulmonary diffusing factors, however, seems to be likely only in extreme conditions such as in highly fit subjects (particularly older) and at high altitudes (23). On the other hand, it should be recognized that the absence of an independent predictive role of $\mathrm{DL}_{\mathrm{CO}} \mathrm{SB}$ for $\dot{\mathrm{V}}_{2}$ max is probably linked to the high degree of multi-colinearity between aerobic power and age and height (Table 1), and the multiple regression analysis is not an adequate approach for evaluating such a cause-
Figure 4 - Positive relationship between oxygen uptake at maximum cycle ergometry $\left(\mathrm{V}_{2}\right.$ max, $\mathrm{ml} / \mathrm{min}$ ) and the carbon monoxide diffusing capacity ( $\mathrm{D}\left\llcorner_{\mathrm{CO}} \mathrm{SB}\right)$. The slope of this relationship was similar in both sexes (35.36) but with different intercepts (979 in males and 455 in females, SEE $=387, \mathrm{P}<0.01$ ). The regression line is presented with the $95 \%$ confidence limit $(C L)$. Rsq is the coefficient of determination. 
effect relationship (18). Even so, although our $\mathrm{DL}_{\mathrm{CO}} \mathrm{SB}$-based prediction equation for $\dot{\mathrm{VO}}_{2}$ max had only a moderate predictive power with a rather higher SEE (Figure 2), it could be used with some necessary caution to estimate $\mathrm{V}_{2}$ max in healthy subjects.

In summary, we have presented a new frame of reference to evaluate the normality of the carbon monoxide diffusing capacity of the lungs ( $\left.\mathrm{DL}_{\mathrm{CO}} \mathrm{SB}\right)$ which was obtained from a randomly selected sample of adult Brazilians. Since previous equations, using predominantly Caucasian subjects $(3,17,18)$, overestimated the observed values at low values and underestimated them at high values, the use of these equations based on subjects from other countries with an "adjusting factor" is not advisable. Our results, however, should be compared with those obtained for males and females aged 20 to 80 years submitted to the same standardized single-breath technique. Additionally, the validity of these reference values should be assessed further in other Brazilian samples of different ethnic and geographical backgrounds.

\section{Acknowledgments}

The authors thank Prof. Dr. Adauto Castelo Filho and Antonio C. Silva (EPM, UNIFESP) for helpful comments; Luíza Hashimoto, Maura Hashimoto, Daniel Siquieroli, Márcio Tonini and Vera Rigoni from the Pulmonary Function and Exercise Laboratories of the Pulmonary Division (EPM, UNIFESP) for competent technical assistance; Marcello DiPietro for his excellent work in preparing the data storage software system (CPX Data); the technical staff of the LAFIREX - Exercise Laboratory of the Department of Physiology (EPM, UNIFESP) for performing the isokinetic dynamometry; the Endocrinology Division of EPM, UNIFESP for providing the DEXA system, and principally all of the participants for their efforts and cooperation. Additionally, the authors are indebted to Mrs. Pat Chapman (Department of Physiology, St. George's Hospital Medical School, London) for her competent revision of the English language.

\section{References}

1. Crapo RO \& Forster RE (1989). Carbon monoxide diffusing capacity. Clinics in Chest Medicine, 10: 187-198.

2. Ruppel G (1994). Lung volume tests. In: Ruppel G (Editor), Manual of Pulmonary Function Testing. 6th edn. Mosby, St. Louis, 1-25.

3. Crapo RO \& Gardner RM (1987). Single breath carbon monoxide diffusing capacity (transfer factor): recommendations for a standard technique. American Review of Respiratory Diseases, 136: 1299-1303.

4. Cotes J E, Chinn DJ, Quanjer PH, RocaJ \& Yernault J C (1993). Standardization of the measurement of transfer factor (diffusing capacity). Report Working Party "Standardization of Lung Function Tests". European Community for Steel and Coal. European Respiratory J ournal, 16: S41S52.

5. American Thoracic Society (1991). Lung function testing. Selection of reference values and interpretative strategies.
American Review of Respiratory Diseases, 144: 1202-1218.

6. Neder J A, Andreoni S, Castelo Filho A \& Nery LE (1999). Reference values for lung function tests. I. Static volumes. Brazilian J ournal of Medical and Biological Research, 32: 703-717.

7. Neder J A, Andreoni S, Lerario MC \& Nery LE (1999). Reference values for lung function tests. II. Maximal respiratory pressures and voluntary ventilation. Brazilian $\mathrm{J}$ ournal of Medical and Biological Research, 32: 719-727.

8. Morris AH \& Crapo RO (1985). Standardization of computation of single-breath transfer factor. Bulletin of the European Society of Physiopathology Respiratory, 21: 183-188.

9. Chinn DJ, Cotes J E, Flowers R, Marks AM \& Reed JW (1996). Transfer factor (diffusing capacity) standardized for alveolar volume: validation, reference values and application of a new linear model to replace KCO (TL/NA). European Respiratory J ournal, 9: 1269-1277.

10. Marrades RM, Diaz O, Roca J, Campistol J M, Torregrosa J V, Barbera J A, Cobos A, Felez MA \& Rodriguez-Roisin R (1997). Adjustment of DLCO for hemoglobin concentration. American J ournal of Respiratory and Critical Care Medicine, 155: 236241.

11. Quanjer PhH, Tammeling GJ, Cotes J E, Pedersen OF, Peslin R \& Yernault J-C (1993). Lung volumes and forced ventilatory flows. Report Working Party "Standardization of Lung Function Tests". European Community for Steel and Coal. European Respiratory J ournal, 6 (Suppl 16): S5-S40.

12. Gaensler EA \& Smith AA (1973). Attachment for automated single breath diffusing capacity measurement. Chest, 63: 136-141.

13. Ogilivie CM, Forster RE, Blakemore WS \& Morton J W (1957). A standardized breath 
holding technique for the clinical measurement of the diffusing capacity of the lung for carbon monoxide. J ournal of Clinical Investigation, 36: 1-17.

14. Statistical Package for Social Sciences (SPSS, IBM +) (1990). Version 6.20.1.

15. Kleinbaum DG, Kupper $L L \&$ Muller $A E$ (1988). Applied Regression Analysis and Other Multivariable Methods. 2nd edn. Duxbury Press, Belmont.

16. Holiday DB, Ballard JE \& McKeown BC (1995). PRESS-related statistics: regression tools for cross-validation and case diagnostics. Medicine and Science in Sports and Exercise, 27: 612-620.

17. Paoletti P, Viegi G, Pistelli G, Di Pede F, Fazzi P, Polato P, Saeta M, Zombon R \&
Giuntini E (1985). Reference equations for the single-breath diffusing capacity: a cross-sectional analysis and effect of body size and age. American Review of Respiratory Diseases, 132: 806-811.

18. Knudson RJ , Kaltenborn WT, Knudson DE \& Burrows B (1987). The single-breath carbon monoxide diffusing capacity: reference equations derived from a healthy nonsmoking population and effects of hematocrit. American Review of Respiratory Diseases, 135: 805-809.

19. Weisman IM \& Zeballos RJ (1987). Lower single breath carbon monoxide diffusing capacity (DLCO) in black subjects compared to Caucasians. Chest, 92 (Suppl): 142S-144S.
20. Stam $H$, Hrachovina $V$, Stijnen $T \&$ Versprille A (1994). Diffusing capacity dependent on lung volume and age in normal subjects. J ournal of Applied Physiology, 76: 2356-2363.

21. Frans A, Nemery B, Veriter C, Lacquet $L$ \& Francis C (1997). Effect of alveolar volume on the interpretation of single breath DLCO. Respiratory Medicine, 91: 263273.

22. Ray CS, Sue DY, Bray G, Hansen JE \& Wasserman K (1983). Effects of obesity on respiratory function. American Review of Respiratory Diseases, 128: 501-506.

23. Whipp BJ (1994). The bioenergetic and gas exchange basis of exercise testing. Clinics in Chest Medicine, 15: 173-192. 